\title{
The Optimal Fitting Model for Aging-related Receptive Field Size Curve of Macaque V1 Neurons
}

\author{
JunHui Cui \\ Yunnan University \\ Department of Electronic Engineering, Information \\ School \\ Kunming, China \\ e-mail:916586214@qq.com \\ HongWei Ding \\ Yunnan University \\ Department of Electronic Engineering, Information \\ School \\ Kunming, China \\ email:dhw1964@163.com
}

\author{
Long Wang \\ Yunnan University \\ Department of Electronic Engineering, Information \\ School \\ Kunming, China \\ email:347654288@qq.com
}

\section{Jing Qiang}

Xi'an Electronic and Science University

Department of Electronic Engineering,

Xi'an ,China

email:770552665@qq.com

\begin{abstract}
Visual function in humans degrades during the early stage of senescence beginning from middle $50 \mathrm{~s}$ to $60 \mathrm{~s}$. Generally,it may derive from the general decline of cortex inhibition, which destroys the balance between excitation and inhibition system in the brain.To date, the optimal fitting model of receptive field size curve is not clear during different age groups.To address this issue, firstly,we carried out extracellular single-unit studies of the receptive field properties of cells in the primary visual cortex(v1) in young and old rhesus monkeys.By IGOR,we obtain the original data of receptive field size curve. Secondly, we use the existing models of Gaussian, DOG (subtractive) and a normalization (divisive) model to fit the data.After that,we found clear indications:The fitting goodness of DOG has a high degree during different age groups and the DOG model has better adaptability and flexibility.In addition,we can draw a conclusion:In aging process, the turning curvature of receptive field size curve of $\mathrm{V} 1$ cells changes obviously, and the surround suppression of the receptive field decreases clearly.
\end{abstract}

Keywords-Visual system;excitation and inhibition;receptive field;fitting model;fitting goodness

\section{INTRODUCTION}

In present,the trend of aging develops rapidly.Human dysfunction followed by the aging affects people's life and work gradually.Visual function in humans degrades in the aging process. Thus, Visual system is a good model for the study.

\section{A. Receptive field}

In primary visual cortex, receptive fields are much more diverse and more complicated.It has two regions:central exciting region and surround suppression region. When presenting a visual stimulation in the surrounding of receptive field,it is capable of regulating exciting response of receptive field prohibitory. When showing a gradual increasing visual stimulation in the receptive fields of visual cells, firstly, the cells's reaction increases gradually, then it may reach a peak, finally, it decreases gradually.Thus, it forms a curve called "receptive field size curve".We use the existing models of Gaussian, DOG and Divisive models to fit the data respectively.

\section{B. Gaussian Model}

Information is integrated across the visual field to transform local features into a global percept. We used drifting sinusoidal gratings in circular and annular apertures to estimate the sizes of the receptive field's excitatory center and suppressive surround.We use combinations of stimuli inside and outside the receptive field to explore the nature of the surround influence on the receptive field center as a function of the relative and absolute contrast of stimuli in the two regions. We then develop a receptive field model based on the ratio of signals from Gaussian-shaped center and surround mechanisms.

\section{DOG Model}

The area-summation profiles derived from experiments done with drifting sine wave gratings in cat Visual cortex are well described by a difference of integrated Gaussians (DeAngelis et al. 1994). In this model, the center Gaussian corresponds to the excitatory or classical receptive field while the surround Gaussian corresponds to the suppressive component of the receptive field. The excitatory or classical receptive field of simple cells has been modeled by as either a Gabor filter or the difference of overlapping Gaussians. 


\section{Divisive Model}

The DOG model proposes that excitation and inhibition interact in an additive manner. Other studies have shown that cortical inhibition might act through a divisive rather than a subtractive mechanism (Albrecht and Geisler 1991; Bonds 1989; Robson et al. 1988). A computational model by Somers et al. (1998) described the cortex as a neural network of center-surround units. Inhibition in this model was also divisive in nature. To compare these two types of interaction, we fit our summation data with the center-surround DOG model and a center-surround normalization model.

\section{MATERIAL AND METHODS}

\section{A. Animals}

Four young and three old male rhesus monkeys (Macaca mulatta) were used in this study.Young monkeys were $2.1-6.1 \mathrm{~kg}$ with a mean age of 5.5 years, and old monkeys were $5.6-9.5 \mathrm{~kg}$ with a mean age of 28 years. An initial ophthalmological examination was performed under ketamine $(100 \mathrm{mg} / \mathrm{kg}$ i.m., Ketalar, Parke-Davis, Morris Plains, NJ, USA) anesthesia to screen for monkeys with ocular pathology.

\section{B. Visual Stimulation}

For each isolated single unit, the eye preference was determined and all subsequent stimuli were presented monocularly to the dominant eye.The receptive field of each cortical neuron was initially located using a bar of light that was optically back-projected onto a tangent screen in front of the monkey.Visual stimuli were generated on these displays by a dedicated computer that employs two high-resolution graphics boards (Imagraph).

\section{Data Collection and Process}

The program to generate the visual stimuli was written in MATLAB, using the extensions provided by the highlevel Psychophysics Toolbox (Brainard 1997) and lowlevel Video Toolbox (Pelli 1997). IGOR software were used for data processing and analysis for primary visual cortex neuron unit discharge signal.Finally, we can obtain the original data of receptive field size curve.

\section{DATA ANALYSIS}

\section{A. Gaussian Model}

Each summation curve was fitted using the following empirical function

$$
R(i)=R_{i}+K_{i} \int_{-s / 2}^{s / 2} e^{-(2(y-b) / a)^{2}} d y
$$

With increasing range of stimulus, there is the whole process of excitation and inhibition of the receptive field.Take $\mathrm{Ri}$ as the initial degree of excited response, integration as function of excitation and inhibition.Valid values of $\mathrm{Ki}, \mathrm{b}, \mathrm{a}$ are selected so that Gaussian curve and "excitation and inhibition"curve are approximate. Finally,we can get the approximating function which reflects the receptive field size curve of excited response exactly.

\section{B. DOG Model}

Each summation curve was fitted using the following empirical function

$$
R(s)=R_{0}+K_{e} \int_{-s / 2}^{s / 2} e^{-(2 y / a)^{2}} d y-K_{i} \int_{-s / 2}^{s / 2} e^{-(2 y / b)^{2}} d y
$$

Here, $R_{0}$ is the spontaneous rate, and each integral represents the relative contribution from putative excitatory and inhibitory components respectively (DeAngelis et al. 1994). Values of Ke, a, Ki, and b were optimized to provide the least mean squared error (MSE) to the data. Excitatory space constant measures are taken as the parameter a from the fitted curves for the first harmonic response of simple cells and the DC response of complex cells.

\section{Divisive Model}

A suppression index (SI) measure was also estimated from the fitted curves. This measure is the ratio of area under the inhibitory Gaussian over that of the excitatory Gaussian

$$
S I=\left(K_{i} b / K_{e} a\right)
$$

We also considered a normalization model of the following form

$$
\begin{gathered}
R(s)=\left(\frac{C K_{c} L_{c}}{1+C K_{s} L_{s}}\right)^{\beta} \\
L_{c}=\int_{-s / 2}^{s / 2} e^{-\left(2 y / r_{c}\right)^{2}} d y \quad L_{s}=\int_{-s / 2}^{s / 2} e^{-\left(2 y / r_{s}\right)^{2}} d y
\end{gathered}
$$

Where Lc and Ls are linear responses estimated from the integral of a Gaussian profile similar to the DOG model discussed in the preceding text. The center and surround gains are $\mathrm{kc}$ and $\mathrm{ks}$, respectively, $\mathrm{C}$ corresponds to the stimulus contrast, and $\beta$ is an arbitrary exponent.

\section{RESULTS}

We studied a total of 38 neurons in each young monkeys and 17 neurons in each old monkeys. In most monkeys. Neurons studied in both age groups were recorded from the same range of cortical depths to avoid laminar bias. They also had similar eccentricities of the receptive fields (less than $8^{\circ}$ ). There was no difference in the thickness of V1 in coronal sections.

\section{A. The Fitting Curve}

All fitting procedures were done with the 1stopt (First Optimization).It have a set of integrated software packages of mathematical optimization and analysis.In the nonlinear regression ,curve fitting and so on ,it can solve complex engineering fields .No exaggeration to say that it has been in leading position.Based on the three models,we write the corresponding function,and select the appropriate fitting algorithm, for example:LevenbergMarquardt(LM), set convergence judgment index as 1.00E10 and maximum number of iterations as 100.Choose a group data of receptive field size of young or old randomly.Write the fitting procedure.Then we can get different kinds of chart.As shown in Fig .1: 

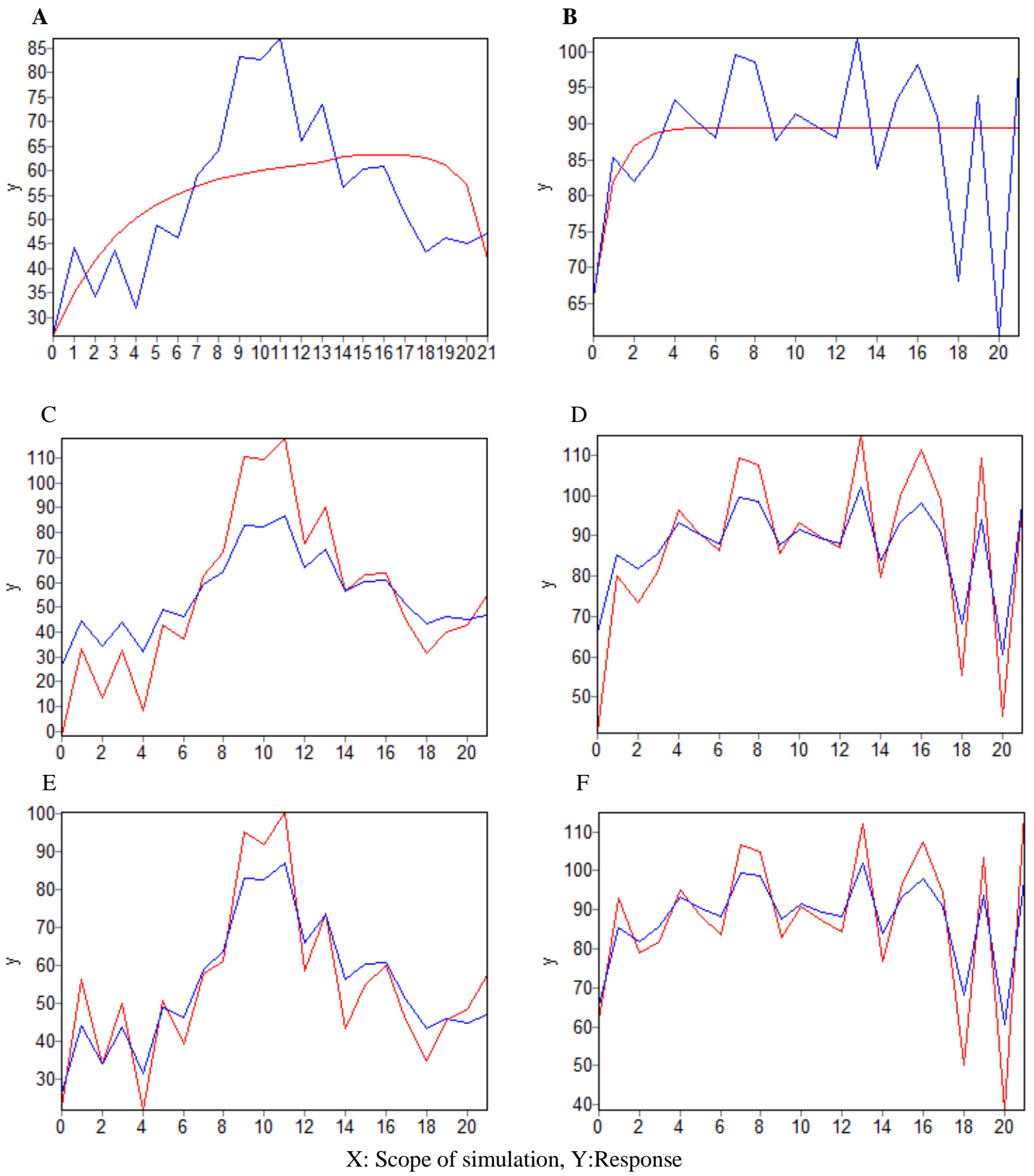

- X-Y Line (actual value); — X-Y Line (calculated or experimental value)

Figure 1. X-Y chart of aging-related receptive field size curve of macaque V1 neurons.

A:Gaussian-Young,B:Gaussian-Old,C:DOG-Young,D:DOG-Old,E :Divisive-Young ,F:Divisive-Old.

\section{B. The Analysis of Fitting Goodness}

With regard to the original data of receptive field size curve from young and old rhesus monkeys,we use 1stopt to analyze each group one by one, and they are calculated under the current three models:Gaussian, DOG and Divisive.

We can get: RMSE, SSE ,R, R2 ,DC, Chi-Square,FStatistic respectively.Then we calculated the mean values of all.For each cell,the minimized criterion is based on the mean square error between the model's response and the experimental data.So we can easily find the intrinsic regularity from distributed data.The fitting parameters related to the fitting curve of receptive fields are shown in Table1. 
TABLE I. STATISTICS OF FITTED MODELS WITH THE POPULATION MEAN $\mathrm{R}^{2}$ VALUES AND THEIR RESPECTIVE MEAN VARIANCE

\begin{tabular}{|c|c|c|c|}
\hline $\begin{array}{c}\text { Analysis } \\
\text { Model }\end{array}$ & $\begin{array}{c}\text { Mean } \\
\text { variance }\end{array}$ & $\begin{array}{c}\text { Correlation } \\
\text { Coefficient(R) }\end{array}$ & $\begin{array}{c}\text { Fitting } \\
\text { Goodness } \\
\mathbf{( R}^{2} \mathbf{~}\end{array}$ \\
\hline $\begin{array}{c}\text { Gaussian_- } \\
\text { Young }\end{array}$ & 3.0028 & 0.7298 & 0.5326 \\
\hline $\begin{array}{c}\text { Gaussian_- } \\
\text { Old }\end{array}$ & 4.7277 & 0.8875 & 0.7877 \\
\hline $\begin{array}{c}\text { DOG_ } \\
\text { Young }\end{array}$ & 1.2549 & 0.9583 & 0.9184 \\
\hline $\begin{array}{c}\text { DOG_Old } \\
\text { Divisive_ } \\
\text { Young }\end{array}$ & 4.2066 & 0.9120 & 0.8317 \\
\hline Divisive-Old & 4.2571 & 0.9582 & 0.9181 \\
\hline
\end{tabular}

\section{SUMMARY}

In this study, we carried out extracellular single-unit studies of the receptive field properties of cells in the primary visual cortex (area V1) in young and old rhesus (Macaca mulatta) monkeys, and studied a total of 81 neurons from them. By IGOR,we obtain the original data of receptive field size curve. This prepared for the investigation of the optimal fitting model for aging-related receptive field size curve of primary visual cortex neurons in monkeys.

The primary finding of this study is that the functions of cells to inhibit the excitation in old monkeys exhibited significantly lower than young monkeys. We also can draw the conclusion that:In the aging process, the turning curvature of receptive field size curve of V1 cells changes obviously, and the surround suppression of the receptive field of $\mathrm{V} 1$ cells also decreases clearly.

Another finding of this study is as follows:

On the one hand, from the fitting curves we can see, the two models of DOG and Divisive are more mature than the Gaussian model. The two models yield quantitatively similar estimates of receptive field size. However,the normalization (divisive) model predicts weaker surround strength than the DOG model,and the fitting goodness of DOG model has a high degree during different age groups in monkeys.

On the other hand, for old monkeys, the fitting goodness is no more than 85 both under DOG and Divisive models, which also demonstrates the limitations of DOG and Divisive model. Since the two models are based on the theory of the receptive field of strong, young and active cells. This phenomenon can be explained as follows: With the loss of cell activity in the aging progress, it has great influence on the inhibitory effect of cells. In that case, the response of Gauss curve is limited. Furthermore, in order to obtain further insight into the relationship between the neuronal changes and the visual degradation in aging, put forward a new model to fit the data of receptive field size would be necessary the next step.

\section{ACKNOWLEDGMENT}

This work was supported by the National Natural Science Foundation of China (61072079,61461053); Natural Science Foundation of Yunnan Province (2010CD023); Graduate Scientific Research Fund of Yunnan University (ynuy201047) financial support of Yunnan University(No.XT412004). This work was also supported by radio and Television Bureau of Yunnan province innovation platform project.

\section{REFERENCES}

[1] Spear PD. Neural bases of visual deficits during aging. Vision Res 1993; 33:2589-2609.

[2] Spear PD, Moore RJ, Kim CB, Xue JT, Tumosa N. Effects of aging on the primate visual system: spatial and temporal processing by lateral geniculate neurons in young adult and old rhesus monkeys. J Neurophysiol 1994; 72:402-420.

[3] Shan YU, Xiusong W, Yu FU, Jie Z, Yuanye MA, Yongchang W et al. Effects of age on latency and variability of visual response in monkeys. Chinese Science Bulletin 2005; 50:1163-1165.

[4] Wang Y, Zhou Y, Ma Y, Leventhal AG. Degradation of signal timing in cortical areas V1 and V2 of senescent monkeys. Cereb Cortex 2005; 15:403-408.

[5] Wang H, Xie X, Li X, Chen B, Zhou Y. Functional degradation of visual cortical cells in aged rats. Brain Res 2006; 1122:93-98.

[6] Zhang J, Wang X, Wang Y, Fu Y, Liang Z, Ma Y et al. Spatial and temporal sensitivity degradation of primary visual cortical cells in senescent rhesus monkeys. Eur J Neurosci 2008; 28:201-207.

[7] Schmolesky MT, Wang Y, Pu M, Leventhal AG. Degradation of stimulus selectivity of visual cortical cells in senescent rhesus monkeys. Nat Neurosci 2000; 3:384-390.

[8] Hua T, Li X, He L, Zhou Y, Wang Y, Leventhal AG. Functional degradation of visual cortical cells in old cats. Neurobiol Aging 2006; 27:155-162.

[9] Liang Z, Yang Y, Li G, Zhang J, Wang Y, Zhou Y et al. Aging affects the direction selectivity of MT cells in rhesus monkeys. Neurobiol Aging 2010; 31: 863-873

[10] Yang Y, Zhang J, Liang Z, Li G, Wang Y, Ma Y et al. Aging Affects the Neural Representation of Speed in Macaque Area MT. Cereb Cortex 2009; 19:1957-1967.

[11] Yu S, Wang Y, Li X, Zhou Y, Leventhal AG. Functional degradation of extrastriate visual cortex in senescent rhesus monkeys. Neuroscience 2006; 140:1023-1029.

[12] Leventhal AG, Wang Y, Pu M, Zhou Y, Ma Y. GABA and its agonists improved visual cortical function in senescent monkeys. Science 2003; 300:812-815

[13] Jones HE, Grieve KL, Wang W, Sillito AM. Surround suppression in primate V1. J Neurophysiol 2001; 86:2011-2028.

[14] Sceniak MP, Hawken MJ, Shapley RM. Visual spatial characterization of macaque V1 neurons. J Neurophysiol 2001; 85:1873-1887.

[15] Fu Y, Wang XS, Wang YC, Zhang J, Liang Z, Zhou YF, Ma YY The effects of aging on the strength of surround suppression of receptive field of $\mathrm{V} 1$ cells in monkeys. Neuroscience doi: 10.1016/j.neuroscience.2010.05.015

[16] T.Womelsdorf, K.Anton-Erxleben, F.Pieper. and S.Treue.Dynamic shifts of visual receptive fields in cortical area $\mathrm{mt}$ by spatial attention. Nat Neurosci9(9):1156-60, 2006.

[17] T.Womelsdorf, K.Anton-Erxleben,and S.Treue Receptive field shift and shrinkage in macaque middle Temporal area through attentional gain modulation.J Neurosci,28(36):8934-44,2008.

[18] K.Anton-Erxleben, V.Stephan, and S.Treue.Attentional reshapes center-surround receptive field structure in macaque cortical area mt.Cereb Cortex,19(10):2466-78,2009. 
[19] J.H. Reynolds and L.Chelazzi.ALLentional modulation of visual processing.Annu Rev Neurosci.27:611-47, 2004.

[20] R.Desimone and J.Duncan.Neural mechanisms of selective visual attention.Annu Rev Neurosci,18:193-222, 1995.

[21] J.R Cavanaugh,W.Bair,and J.A.Movshon.Narure and interaction of signals from the receptive field center and surround in macaque $\mathrm{vl}$ neurons.J Neurophysiol,88(5):2530-46,2002.
[22] J M.P. Sceniak, M.J. Hawken, and R.Shapley.Visual spatial characterization of macaque vl neurons.

Neurophysiol,85(5): 1873-87, 2001. 